\title{
THE RELATIONSHIP BETWEEN ENERGY CONSUMPTION AND GDP: EVIDENCE FROM A PANEL OF 10 LATIN AMERICAN COUNTRIES*
}

\author{
JаCOBO CAMPO ${ }^{* *}$ \\ ViVianA SARMiento***
}

\begin{abstract}
We estimate the elasticity of the long-run relationship between energy consumption and GDP for 10 countries in Latin America from 1971 to 2007. We employ Pedroni's $(1999,2004)$ panel cointegration test to determine if such a long-run relationship exists. Westerlund's (2006) cointegration test for panel data is used to estimate the slopes of the long-run relationship variables. These findings provide empirical guidance for policies to promote energy conservation and efficiency. Cointegration between the two variables is found to exist in both directions. This paper discusses the energy dependence of some countries and describes potential implementation of energy conservation policies in others.
\end{abstract}

JEL classification: C32, O40, Q43

Keywords: energy consumption, panel stationarity, panel cointegration, Latin America

\section{INTRODUCTION}

In the three decades since Kraft and Kraft's (1978) seminal study, economists and other researchers have studied the relationship between energy consumption and GDP from different perspectives and using diverse methodologies. Their methods have ranged from descriptive time series analysis to cointegration applications with panel data. This paper presents empirical evidence on the long-run relationship between energy consumption and real GDP through the application of a cointegration panel test and estimation methods in both directions, i.e., energy consumption to GDP and GDP to energy consumption.

\footnotetext{
* We would like to thank the referees and editors Raimundo Soto and Felipe Zurita for their valuable suggestions. We are also grateful to José Fernando Moreno Gutierrez, and the seminar participants at Banco de la República, Departamento Nacional de Planeación (DNP), Unidad de Planeación MineroEnergética, Instituto Nacional Politécnico de México and Universidad Católica de Colombia.

** Researcher, Professor and Group Head of Finance and Political Economy, Facultad de Economía, Universidad Católica de Colombia, Cra 13. \# 47 - 49, Bogotá, Colombia. Tel: +57 (1) 3277300 . Email: jacampo@ucatolica.edu.co or jacobo.campo@gmail.com.

*** At the time this article was written, she was a research assistant at the Facultad de Economia, Universidad Católica de Colombia. She is now a research assistant at CAMACOL in Bogotá, Colombia. Email: lvsarmiento48@ucatolica.edu.co or vivianasarmientog@gmail.com.
} 
Governments are interested in studying this relationship because of the international goal of curbing the increase in global temperature to a maximum of $2^{\circ} \mathrm{C}$ in the context of global warming. To achieve this goal, it has become necessary to assess the impacts of policies that promote energy conservation and efficiency on national GDP and economic growth. According to the International Energy Agency (IEA), " $80 \%$ of emissions from the energy sector that were planned for 2020 have already been reached and $40 \%$ of $\mathrm{CO}^{2}$ emissions from OECD countries." This accelerated trend in global emissions represents a step backwards in the battle against global warming. However, some policy makers are concerned that conservative energy efficiency policies, such as those designed and formulated according to researchers' suggestions, may have disastrous results on their countries' economic activity.

The first purpose of this paper is to estimate the relationship between energy consumption and GDP for 10 countries in Latin America. Secondly, we compare these estimates at a regional level and compare them with estimates obtained in other studies. We do this by using recent panel data methods, including developments in the second generation of cointegrated panel data, which accounts for structural breaks and cross-sectional dependence in the long-run relationship. For this method of analysis, we apply unit root tests according to the methodology proposed by Westerlund (2006).

This paper is organized as follows. The second section presents a brief literature review on the topic of energy consumption and GDP. Section 3 presents the methodology used in this study and the data analyzed in our paper. Section 4 presents the estimates and results of our model and compares these results with estimates obtained in previous works. The fifth and final section concludes.

\section{ENERGY CONSUMPTION AND GDP: A BRIEF Literature REVIEW}

Ozturk (2010), Squalli (2007) and Magazzino (2011) provide four hypotheses about the direction of causality between energy consumption and GDP. The first is the hypothesis of neutrality, which holds that there is no causality (in either direction) between these two variables. The second is the energy conservation hypothesis, which holds that there is evidence of unidirectional causality from GDP growth to energy consumption. Under the third hypothesis, which is known as the growth hypothesis, energy consumption drives GDP growth. The fourth hypothesis is the 
feedback hypothesis, which suggests a bidirectional causal relationship between energy consumption and GDP growth.

Several authors have studied the relationship between GDP and energy consumption and have found varying results. For example, Kraft and Kraft (1978) found unidirectional causality from GDP to energy consumption in the United States for the 1947-1974 period. Abosedra and Baghestani (1991) proved the assertion put forth by Kraft and Kraft (1978) by using the standard test of Granger causality. However, Akarca and Long (1980) argue that the results of Kraft and Kraft (1978) are spurious because they found no evidence of causality when the time period is bounded by two-year intervals. $\mathrm{Yu}$ and Hwang (1984) and Yu and Choi (1985) also found no causal relationship between energy consumption and GDP, although they used several different methods.

Erol and $\mathrm{Yu}$ (1987) found bidirectional causality between energy consumption and real GDP in Japan and Italy, a one-way causal relationship in East Germany, and a neutral relationship in France, the United Kingdom and Canada using the Granger causality test. Sims (1972) and Hwang and Gum (1992) found evidence of bidirectional causality between energy consumption and GDP in Taiwan. Fatai (2002) found no relationship between energy consumption and GDP in New Zealand.

In a study by Al-Iriani (2005) for the six countries comprising the Gulf Cooperation Council (Kuwait, Oman, Saudi Arabia, Bahrain, United Arab Emirates, and Qatar), the results indicate that there is unidirectional causality from GDP to energy consumption; Soytas et al. (2001) found evidence of unidirectional causality from energy consumption to GDP in Turkey using a model of cointegration and vector error correction analysis.

Narayan et al. (2010) examine the long-run elasticities of the impacts of energy consumption on GDP in addition to the impacts of GDP growth on energy consumption for 93 countries during the time period from 1980 to 2006. They apply unit root tests and the cointegration test of Pedroni $(1999,2004)$ to calculate long-run elasticities between energy consumption and GDP and GDP and energy consumption. Lee (2005) estimates elasticities based on a capital-driven production function, finding a significant coefficient in the direction of energy consumption to GDP. Later in this paper, we compare the results obtained from our model with the estimates obtained by other researchers in the field. 


\section{Methodology AND DATA}

This paper analyzes information on energy consumption and GDP in 10 countries for the time period between 1971 and 2007. The methodology for estimating long-run elasticities in energy consumption and GDP relationship is given by Westerlund (2006). In this case, we propose estimating the following relationships to find the $\left(\beta_{i}\right)$ for each of the following equations. We will use the index $i=1,2,3, \ldots, N$ to denote countries, and $t=1,2,3, \ldots, T$ to denote time. Consider the following panel regressions:

$$
\begin{aligned}
& G D P_{i t}=\alpha_{i}+\beta_{i} E C_{i t}+\varepsilon_{i t} \\
& E C_{i t}=\alpha_{i}+\beta_{i} G D P_{i t}+\varepsilon_{i t}
\end{aligned}
$$

$G D P_{i t}$ is the real GDP for each country $(i)$ during the period $(t)$, and $E C_{i t}$ is the energy consumption (both variables are scaled in percapita units). Note that $\left(\beta_{i}\right)$ is a country-specific slope (elasticity in this case) that is assumed to be constant over the period from 1971 to 2007 , and $\left(\varepsilon_{i t}\right)$ is the term error.

To avoid spurious regressions, we test the stationarity of the series, which requires the use of panel unit root tests. Next, if the series are not stationary, i.e., if the series have unit roots, then we test whether there is a long-run relationship between the relevant variables. Then we establish the following procedure. First, we apply a panel unit root test to determine the integration order of each variable. Second, we apply the panel cointegration test used by Pedroni (1999, 2004) to determine whether there is a long-run relationship between the model's variables. Finally, we apply the panel cointegration test used by Westerlund (2006) to determine the existence of a long-run relationship between variables, taking into account the cross-sectional dependence and possible structural breaks in the long-run relationship. As a result of the last test, we estimate the long-run coefficients (elasticities) of the variables.

\subsection{Panel unit root tests}

We begin by considering the integration order of the energy consumption and real GDP series using panel unit root tests, following methods used by IPS (2003), Levin, Lin, and Chu (2002), 
Bruiting (2000), Maddala and Wu (1999) (Fisher-type ADF), Choi (2001) (Fisher-type PP), and Hadri (2000). The advantage of the methods used by Maddala and Wu (1999) and IPS (2003) is that these papers relax the assumption of homogeneity. Choi (2001) models cross-sectional dependence by common factors, considering a homogeneous $\mathrm{AR}(1)$ model.

Panel unit root tests are theoretically grounded in a time series approach. Both theory and literature suggest that panel data unit root tests offer advantages over time series data, primarily because panel data combine cross-sectional data units and time series, providing a greater number of degrees of freedom and improving statistical efficiency. Additionally, this approach successfully mitigates the problem of bias that is caused by unobserved heterogeneity in the regression.

\subsection{Panel cointegration tests}

Having established that the two variables are $\mathrm{I}(1)$, i.e., that the variables contain a panel unit root, we next test whether there is a long-run relationship between the variables. First, we follow Pedroni (1999, 2004) by applying a heterogeneous panel cointegration test (first-generation test). Then, we follow Westerlund (2006) by applying a heterogeneous panel cointegration test with multiple structural breaks (second-generation test).

Westerlund (2006) proposes a cointegration test for the null cointegration hypothesis, based on a Lagrange multiplier (LM). This test allows for multiple structural breaks in both the level and trend of a panel regression. Following Westerlund (2006), the panel LM test statistic for this particular hypothesis is defined as follows:

$$
Z(M)=\frac{1}{N} \sum_{i=1}^{N} \sum_{j=1}^{M_{i}+1} \sum_{t=T_{i j-1}+1}^{T_{i j}} \frac{S_{i t}}{\left(T_{i j}-T_{i j-1}\right)^{2} \hat{\sigma}_{i}^{2}}
$$

In this equation, $S_{i t}=\Sigma_{s=T_{i j-1}+1}^{t} \hat{\varepsilon}_{i t}$, and $\hat{\varepsilon}_{i t}$ is the regression error obtained by using the fully modified OLS (FMOLS) estimator. Westerlund (2006) shows that statistic $Z(M)$, which is standardized by its mean and standard deviation, has an asymptotic, standard normal distribution under the null hypothesis. Using the procedure 
from Bai and Perron (2003), Westerlund (2006) estimates the number of breaks and the locations of the breaks in the sample for each country. Westerlund (2006) accounts for the impact of crosscountry dependence and suggests using the bootstrap method. In this case, we use Davison and Hinkley's (1997) block method of bootstrapping. The advantage of this procedure is that the breaks are determined endogenously, whereas in other approaches the breaks are chosen exogenously.

The empirical analysis is based on a panel of 10 countries (Argentina, Bolivia, Brazil, Chile, Colombia, Ecuador, Paraguay, Peru, Uruguay and Venezuela) in Latin America during the 1971 -2007 period. We use a series of per-capita energy consumption and per-capita GDP data from the World Bank. Table 1 presents descriptive statistics of the series for each country.

The per-capita energy consumption series for the 10 countries studied follows a normal distribution, except for Peru. It should be noted that Venezuela has the highest average per-capita power consumption in the region (2276.667 kWh), with a standard deviation of $584.2418 \mathrm{kWh}$. Bolivia reports the lowest average in the region with $311.0732 \mathrm{kWh}$ consumed per person annually, and a standard deviation of $95.23 \mathrm{kWh}$ (See Table 1).

On the other hand, the real per-capita GDP series data follow a normal distribution for all countries except Paraguay. However, the inclusion of structural breaks endogenously estimated and the Westerlund (2006) test allow for modeling behavior in the series that is not normally distributed. Argentina has a real per-capita GDP that is higher than the regional average at USD 7,121.8 with a standard deviation of USD 749.552. In contrast, Paraguay has an average per-capita GDP of USD 1,284.95. This is the lowest figure amongst all the countries, with a standard deviation of USD 195.7014 (see Table 2).

Figure 1 presents graphs of the variables for each of the countries in the sample, both in logarithms and in first differences. In general, these graphs show that in some periods, the variables appear to have strong relationships, but in other periods the directionality of the relationships is reversed. These stylized facts give us an idea of the close relationship between energy consumption and GDP in the Latin American countries under study. Moreover, the graphs in Figure 1 show comovements between the growth rates of the two sets in each of the countries. 


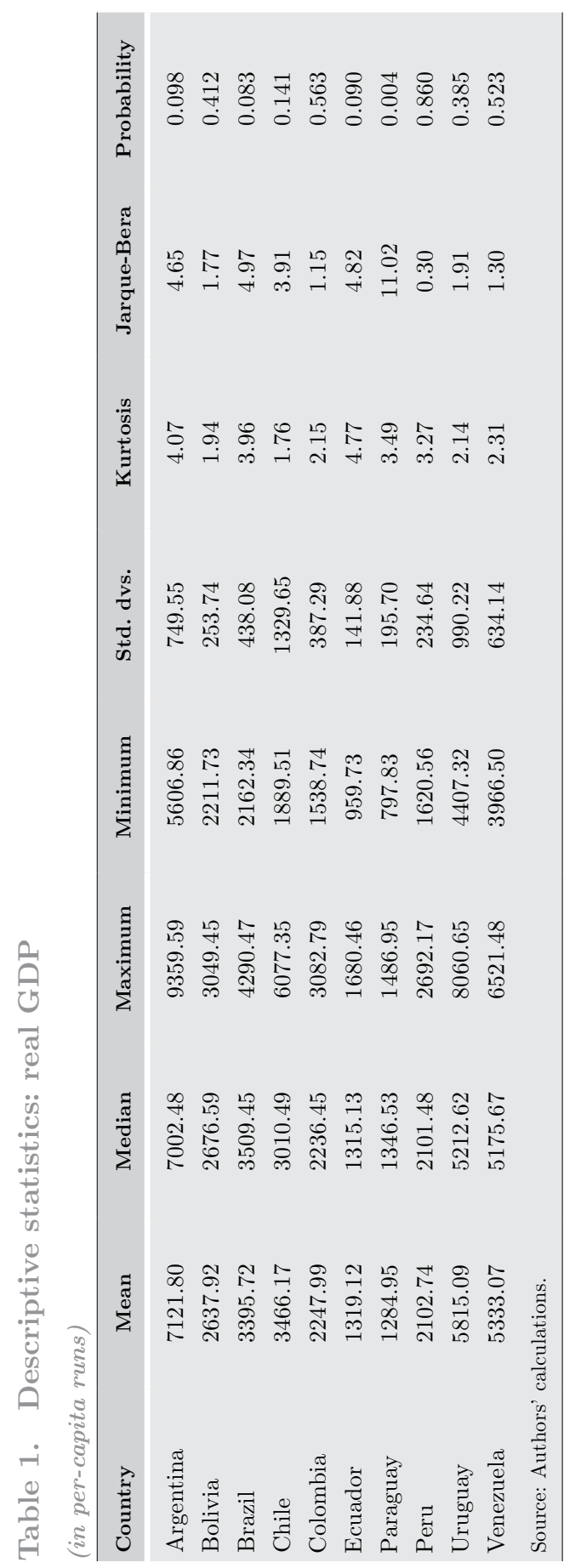




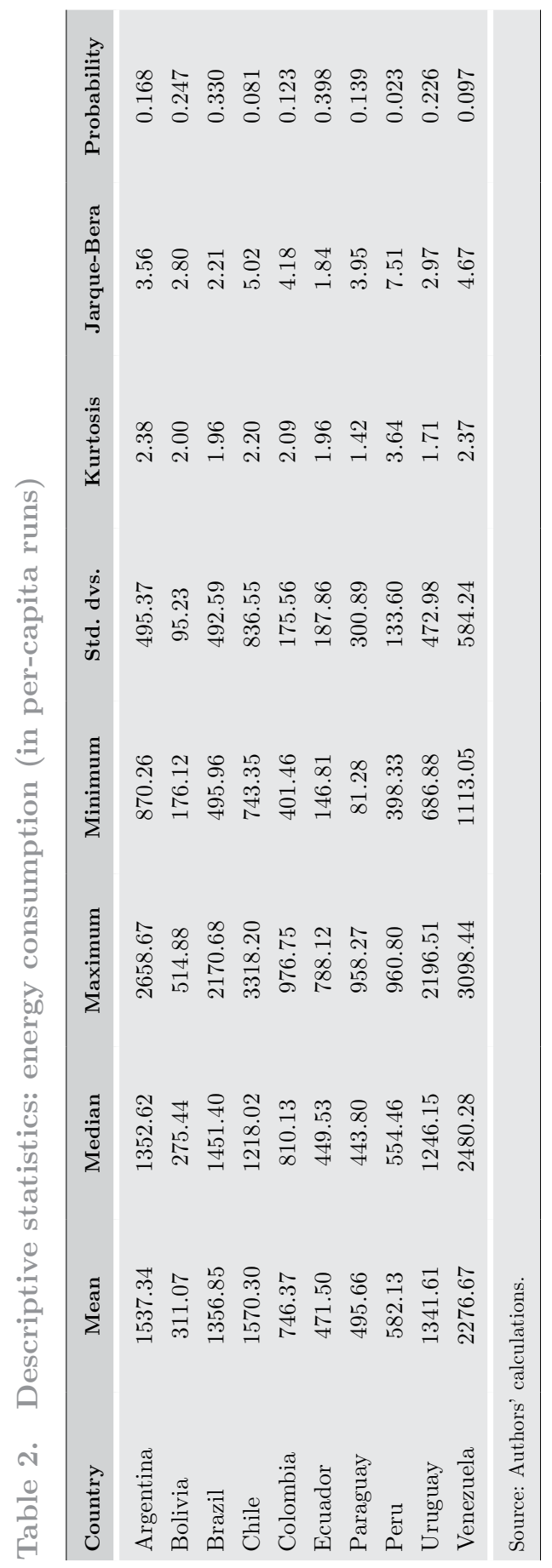


Figure 1. Energy consumption and GDP and first differences (in logarithms)

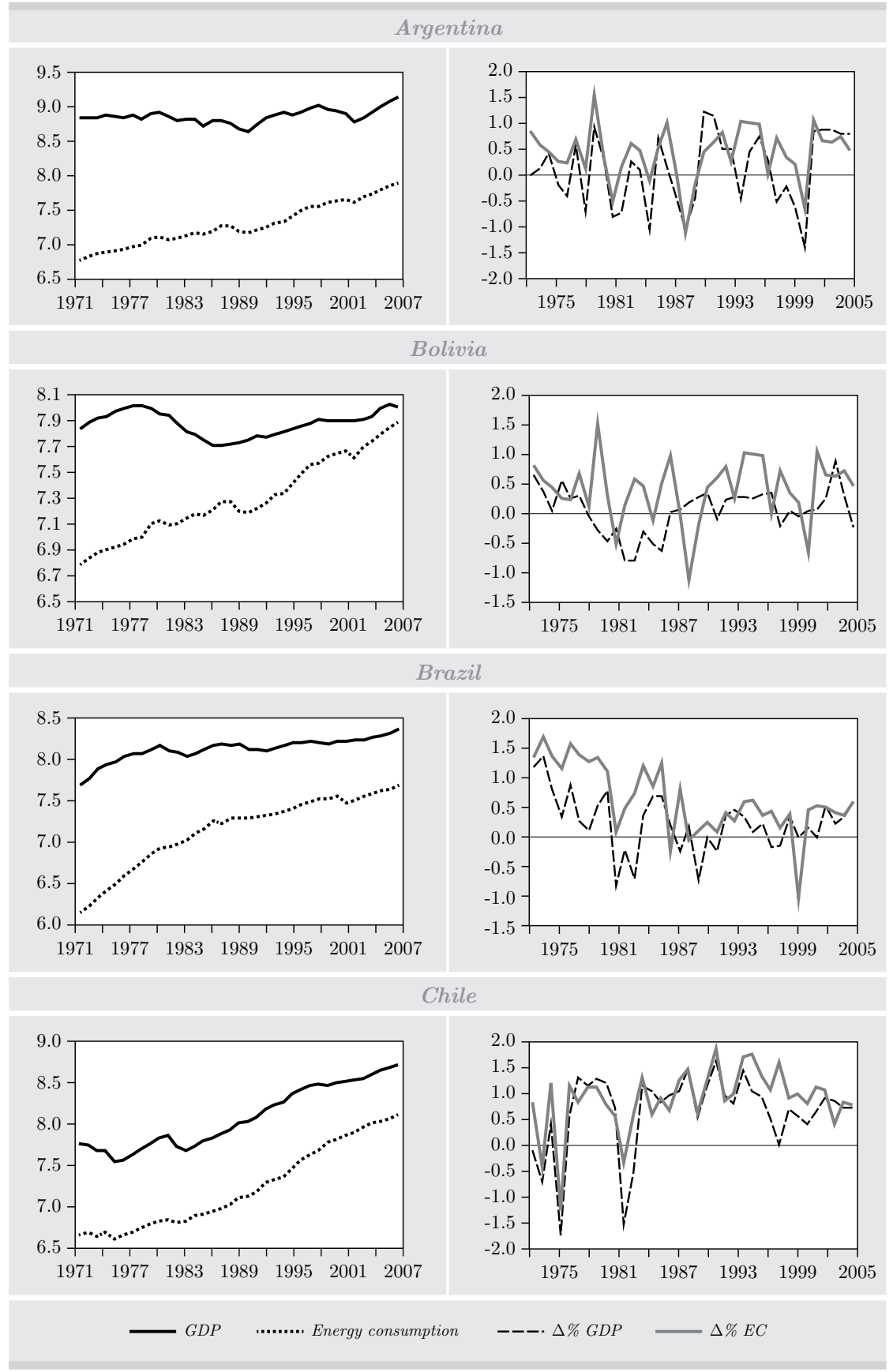


Figure 1. (continued)

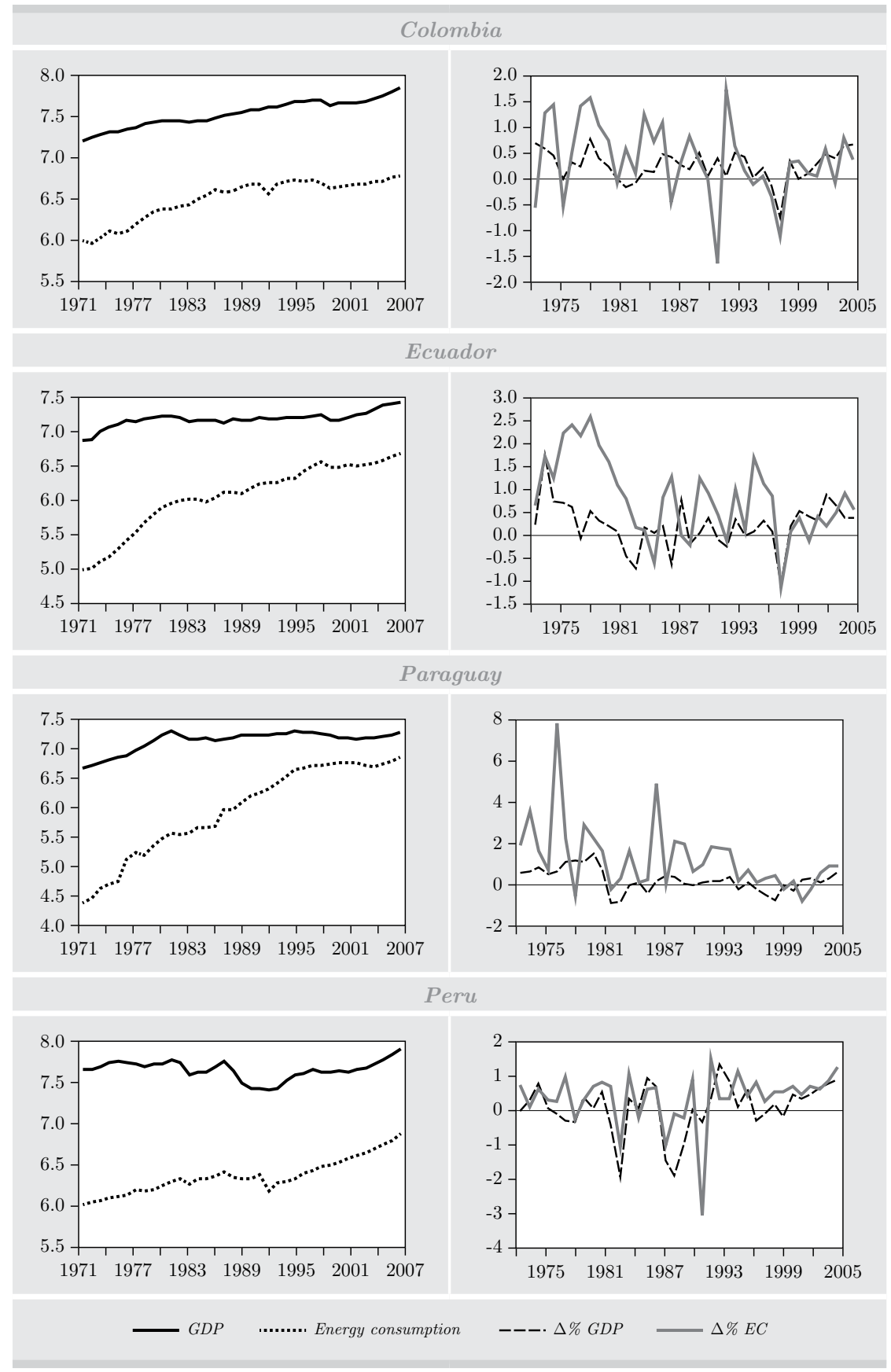


Figure 1. (continued)

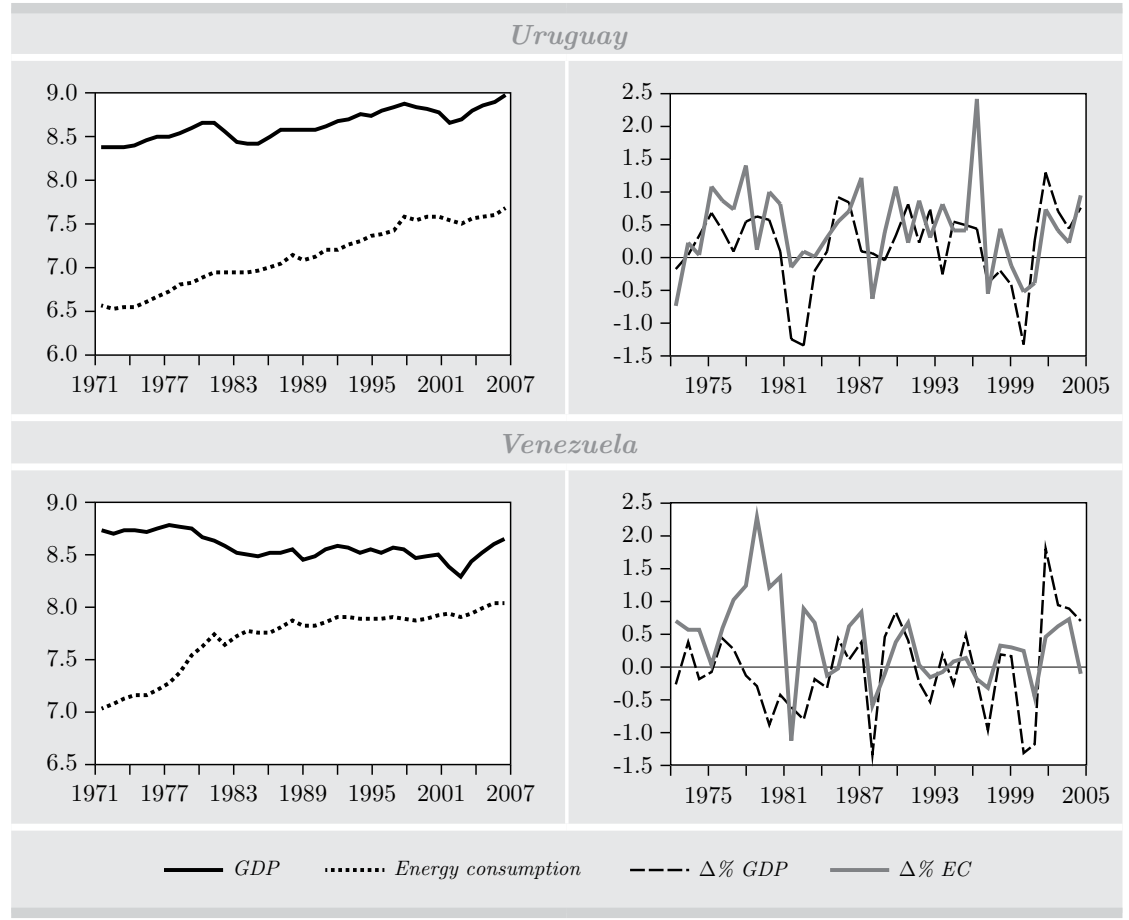

Source: World Bank, 2011.

\section{EstimATIONS AND RESULTS}

In this section, we present the results obtained by using the procedure explained in Section 3. Specifically, we discuss the results of panel unit root tests, the results of the panel cointegration tests, and the estimated long-run elasticities for each country and for the regional subsamples of countries.

\subsection{Panel unit root tests}

The results of the panel unit root tests are reported in Table 3 and Table 4. In Table 3, the results of the unit root analysis suggest that for almost all panel unit root tests, at the $5 \%$ significance level, the logarithm of energy consumption and the logarithm of real GDP are non-stationary for the panel. For the two variables, the null hypothesis of a unit root cannot be rejected at these levels. For IPS, 
Table 3. Panel unit root tests

(levels)

\begin{tabular}{lcccc}
\hline \multirow{2}{*}{ Test } & \multicolumn{2}{c}{ Energy consumption } & \multicolumn{2}{c}{ GDP } \\
\cline { 2 - 5 } & Statistic & Probability & Statistic & Probability \\
Im, Pesaran, and Shin $(W$-statistic) & 1.063 & 0.856 & -0.081 & 0.467 \\
ADF - Fisher $\left(\chi^{2}\right)$ & 12.474 & 0.898 & 25.527 & 0.182 \\
PP - Fisher $\left(\chi^{2}\right)$ & 11.803 & 0.923 & 21.564 & 0.364 \\
Levin, Lin \& Chu $(t$-statistic) & $-1.88^{* *}$ & 0.030 & -0.809 & 0.209 \\
Breitung $(t$-statistic) & 1.497 & 0.933 & $-2.056^{* *}$ & 0.019 \\
Hadri $(Z$-statistic) & $8.069^{* * *}$ & 0.000 & $4.918^{* * *}$ & 0.000
\end{tabular}

Notes: $* * *(* *)$ denote statistical significance at the $1 \%(5 \%)$ level. The optimal lag length was selected automatically using the Schwarz criterion.

\section{Table 4. Panel unit root tests}

\section{(first difference)}

\begin{tabular}{lcccc}
\hline \multirow{2}{*}{ Test } & $\Delta$ (Energy consumption) & \multicolumn{2}{c}{$\Delta$ GDP } \\
\cline { 2 - 5 } & Statistic & Probability & Statistic & Probability \\
Im, Pesaran, and Shin $(W$-statistic) & $-6.7339^{* * *}$ & 0.000 & $-8.016^{* * *}$ & 0.000 \\
ADF - Fisher $\left(\chi^{2}\right)$ & $85.3998^{* * *}$ & 0.000 & $101.49^{* * *}$ & 0.000 \\
PP - Fisher $\left(\chi^{2}\right)$ & $168.42^{* * *}$ & 0.000 & $102.68^{* * *}$ & 0.000 \\
Levin, Lin \& Chu $(t$-statistic) & $-5.333^{* * *}$ & 0.000 & $-8.243^{* * *}$ & 0.000 \\
Breitung $(t$-statistic) & $-6.253^{* * *}$ & 0.000 & $-6.098^{* * *}$ & 0.000 \\
Hadri $(Z$-statistic) & $4.911^{* * *}$ & 0.000 & 1.021 & 0.153 \\
Notes: $* * *(* *)$ denote statistical significance at the $1 \%(5 \%)$ level. The optimal lag length was selected \\
automatically using the Schwarz criterion.
\end{tabular}

ADF (Fisher type), PP (Fisher type), Bruiting, and Hadri tests, the null of stationarity is rejected at the $1 \%$ significance level.

Table 4 presents the results of the unit root tests performed on the series in first differences. The purpose of this test is to verify the existence of additional unit roots, thus determining the order of integration of the series. The results indicate that the difference series are stationary, which implies that the series in levels are integrated by one order, i.e., are $\mathrm{I}(1)$. 


\subsection{Panel cointegration test}

Having established that the two variables are I(1), i.e., that they contain a panel unit root, we proceed to test whether there is a longrun relationship between the two variables. First, we use the Pedroni (1999, 2004) heterogeneous panel cointegration test, and then the Westerlund (2006) heterogeneous panel cointegration test with multiple structural breaks.

Table 5 reports the panel cointegration estimation results. We reject the null hypothesis of no cointegration only for the panel v-statistic. Furthermore, for the relationship between GDP and energy consumption (GDP-EC), none of the statistics allow us to reject the null hypothesis of no cointegration. This finding may have occurred because this test can lead researchers to mistakenly fail to reject the null hypothesis because the test excludes the possible existence of cross-country dependence and the possible structural breaks in the cointegration relationship. For this reason, we choose to apply the Westerlund (2006) test to control for these factors.

\section{Table 5. Pedroni $(1999,2004)$ panel cointegration test}

\begin{tabular}{lcccc}
\hline \multirow{2}{*}{ Within-dimension } & \multicolumn{2}{c}{ EC $\rightarrow$ GDP } & \multicolumn{2}{c}{ GDP $\rightarrow$ EC } \\
\cline { 2 - 5 } & Statistic & $p$-value & Statistic & $p$-value \\
\hline Panel $v$-statistic & $2.721^{* * *}$ & 0.003 & -1.807 & 0.965 \\
Panel Phillips-Perron type $\rho$-statistic & -0.549 & 0.292 & 1.168 & 0.879 \\
Panel Phillips-Perron type $t$-statistic & -0.316 & 0.376 & 1.047 & 0.852 \\
Panel ADF type $t$-statistic & $-1.734^{* *}$ & 0.041 & 0.808 & 0.791 \\
Between-dimension & & & & \\
Group Phillips-Perron type $\rho$-statistic & 0.508 & 0.694 & 1.847 & 0.968 \\
Group Phillips-Perron type $t$-statistic & 0.406 & 0.658 & 1.653 & 0.951 \\
Group ADF type $t$-statistic & -1.281 & 0.100 & 1.349 & 0.911 \\
\hline $\begin{array}{l}\text { Notes: } * * *(* *) \\
\text { automatically } \text { using the Schwarz criterion. }\end{array}$ & & & & \\
\hline
\end{tabular}

Table 6 reports results from the Westerlund $(2006)^{1}$ heterogeneous panel test with multiple breaks, which accommodates cross-sectional 
dependence using the block bootstrapping method developed by Davison and Hinckley (1997). Using a block size of 5 over 1,000 replications, the bootstrap $p$-value for the null hypothesis of cointegration in both cases is 0.98 and 0.93 respectively, indicating rejection of the null hypothesis at any conventional level of significance.

\section{Table 6. Westerlund (2006) panel cointegration test}

\begin{tabular}{|c|c|c|}
\hline \multicolumn{3}{|c|}{ About the method } \\
\hline Estimation method & \multicolumn{2}{|l|}{ FMOLS } \\
\hline Maximun number of breaks & \multicolumn{2}{|l|}{5} \\
\hline Bootstrap method & \multicolumn{2}{|c|}{ Davison and Hinkley Blocks } \\
\hline Block type & \multicolumn{2}{|c|}{ Blocks with geometric distribution } \\
\hline Block size & \multicolumn{2}{|l|}{5} \\
\hline \multirow[t]{2}{*}{ Bootstrap replications } & \multicolumn{2}{|l|}{1,000} \\
\hline & $\mathrm{EC} \rightarrow \mathrm{GDP}$ & GDP $\rightarrow$ EC \\
\hline LM statistic with bootstrapping & 10,671 & 7,357 \\
\hline The $p$-value bootstrap & 0.986 & 0.938 \\
\hline
\end{tabular}

These results provide empirical evidence about the existence of a bidirectional causality, since when estimating long-run relationships through cointegration tests, the magnitude (positive or negative) of the coefficients represents the direction of the causality (Granger, 1983; Engle and Granger, 1987).

Table 7 presents the estimated breaks that are present in the long-run relationship between energy consumption and GDP. It also presents specific breakdowns for the relationship of energy consumption to GDP and GDP to energy consumption. These results suggest that there is strong relationship instability between energy consumption and GDP in Latin American countries during the study period. Note that the Westerlund test detected 35 breaks in the panel for the energy consumption-GDP relationship and detected 36 breaks in the GDPenergy consumption relationship.

The estimations of the long-run elasticities are reported in Table 8. The first column lists the countries, the second column shows the longrun elasticity of energy consumption's impact on GDP, accompanied by its standard deviation, and the last column reports the long-run elasticity of GDP's impact on energy consumption and its standard deviation. For each of the 10 Latin American countries and for the 
Table 7. Estimated breaks

\begin{tabular}{|c|c|c|c|c|c|c|}
\hline \multicolumn{7}{|c|}{ Matrix structural breaks (energy consumption $\rightarrow$ GDP) } \\
\hline Country & Breaks & B1 & B2 & B3 & B4 & B5 \\
\hline Argentina & 3 & 1988 & 1994 & 2002 & - & - \\
\hline Bolivia & 5 & 1975 & 1981 & 1987 & 1997 & 2002 \\
\hline Brazil & 4 & 1980 & 1985 & 1994 & 2000 & - \\
\hline Chile & 3 & 1986 & 1993 & 2000 & - & - \\
\hline Colombia & 2 & 1976 & 1986 & - & - & - \\
\hline Ecuador & 3 & 1975 & 1980 & 1995 & 2002 & - \\
\hline Paraguay & 4 & 1975 & 1986 & 1994 & - & - \\
\hline Peru & 2 & 1981 & 1991 & - & - & - \\
\hline Uruguay & 5 & 1976 & 1981 & 1987 & 1992 & 1997 \\
\hline Venezuela & 4 & 1976 & 1981 & 1988 & 1997 & - \\
\hline \multicolumn{7}{|c|}{ Matrix structural breaks (GDP $\rightarrow$ energy consumption) } \\
\hline Argentina & 3 & 1987 & 1994 & 2002 & - & - \\
\hline Bolivia & 3 & 1977 & 1986 & 2000 & - & - \\
\hline Brazil & 3 & 1975 & 1982 & 2000 & - & - \\
\hline Chile & 4 & 1975 & 1981 & 1995 & 2002 & - \\
\hline Colombia & 4 & 1979 & 1985 & 1997 & 2002 & - \\
\hline Ecuador & 3 & 1981 & 1995 & 2002 & - & - \\
\hline Paraguay & 5 & 1975 & 1981 & 1987 & 1996 & 2001 \\
\hline Peru & 4 & 1982 & 1988 & 1993 & 2002 & - \\
\hline Uruguay & 4 & 1979 & 1984 & 1996 & 2001 & - \\
\hline Venezuela & 3 & 1978 & 1983 & 2001 & - & - \\
\hline
\end{tabular}

regional subsample (panel), the long-run elasticities of the impact of energy consumption on real GDP indicate a bidirectional, long-run relationship between real GDP and energy consumption. Moreover, a 1 percent increase in energy consumption increases real GDP by $0.59 \%$ across the entire panel; a 1 percent increase in real GDP increases energy consumption by $0.59 \%$ across the entire panel. As mentioned previously, these results represent bidirectional causality, because when long-run relationships are estimated using cointegration tests, the magnitude (positive or negative) of the coefficients represents the direction of the causality (Granger, 1983; Engle and Granger, 1987). For example, Lee and Chang (2007) explore the direction of causality between energy consumption and GDP through a dynamic panel in a sample of developed and developing countries. 
Table 8. Panel cointegration slope estimates (long-run elasticities)

\begin{tabular}{lcccc}
\hline \multirow{2}{*}{ Country } & \multicolumn{2}{c}{$G D P_{i t}=\alpha_{i}+\beta_{i} E C_{i t}+\varepsilon_{i t}$} & \multicolumn{2}{c}{$E C_{i t}=\alpha_{i}+\beta_{i} G D P_{i t}+\varepsilon_{i t}$} \\
\cline { 2 - 5 } & $\begin{array}{c}\text { Elasticity } \\
\text { (slope) }\end{array}$ & S.D. & $\begin{array}{c}\text { Elasticity } \\
\text { (slope) }\end{array}$ & S.D. \\
Argentina & 1.433 & 0.108 & 0.533 & 0.039 \\
Bolivia & 0.214 & 0.073 & 0.18 & 0.141 \\
Brazil & 1.236 & 0.002 & 0.189 & 0.052 \\
Chile & 1.141 & 0.002 & 0.4 & 0.058 \\
Colombia & 0.154 & 0.068 & 0.815 & 0.002 \\
Ecuador & 0.204 & 0.031 & 0.739 & 0.003 \\
Paraguay & 0.115 & 0.027 & 0.693 & 0.004 \\
Peru & 0.379 & 0.180 & 0.786 & 0.003 \\
Uruguay & 0.367 & 0.094 & 0.783 & 0.004 \\
Venezuela & 0.655 & 0.232 & 0.82 & 0.003 \\
Regional & $\mathbf{0 . 5 9 0}$ & $\mathbf{0 . 0 8 2}$ & $\mathbf{0 . 5 9 4}$ & $\mathbf{0 . 0 3 1}$ \\
Note: Regional slope is an average of all 10 countries. & & \\
\hline
\end{tabular}

On a per-country basis, the cointegration results show that for all countries the slopes have a positive sign and are statistically significant. In other words, energy consumption has a positive impact on GDP. In the cases of Argentina, Brazil and Chile, energy consumption exerts a positive and elastic effect on real GDP, whereas in the cases of Colombia and Paraguay energy consumption has a positive but smaller effect on real GDP.

Regarding the relationship between real GDP and energy consumption, these findings show that for all countries, GDP has a positive effect on energy consumption. In the cases of Colombia and Venezuela, a 1\% increase in real GDP increases energy consumption by $0.82 \%$. This result demonstrates compliance with the feedback hypothesis, which holds that there is a bidirectional relationship between these two variables. Other studies such as Narayan et al. (2010) and Lee (2005) also estimated long-run elasticities for some of the countries included in our sample. Table 9 presents these authors' results. We observe that the results of Narayan et al. (2010) are similar to those obtained in this paper for Argentina and Venezuela. However, our results differ from the estimates shown in Table 9, particularly for Colombia, but these results are not statistically significant. Finally, the results of Lee (2005) are similar to our estimates, but differ in the case of Venezuela. 
Table 9. Other results of long-run elasticities

\begin{tabular}{lcccc}
\hline & \multicolumn{2}{c}{ Narayan et al (2010) } & & Lee (2005) \\
\cline { 2 - 3 } Country & EC $\rightarrow$ GDP & GDP $\rightarrow$ EC & & EC $\rightarrow$ GDP \\
\cline { 2 - 3 } & Elasticity & Elasticity & & Elasticity \\
Argentina & $1.23^{* *}$ & $0.43^{* *}$ & & $0.84^{* *}$ \\
Bolivia & $1.95^{* *}$ & $0.25^{* *}$ & - \\
Brazil & 0.29 & 0.26 & - \\
Chile & $0.72^{* *}$ & $1.34^{* *}$ & \\
Colombia & -0.7 & -0.11 & $0.83^{* *}$ \\
Ecuador & $1.05^{* *}$ & $0.44^{* *}$ & \\
Paraguay & - & - & - \\
Peru & $1.42^{* *}$ & $0.44^{* *}$ & - \\
Uruguay & $1.72^{* *}$ & $0.27^{* *}$ & \\
Venezuela & $0.85^{* *}$ & $1.09^{* *}$ & \\
Regional & $0.91^{* *}$ & $0.43^{* *}$ & - \\
Note: ** denotes statistical significance at the $5 \%$ level. & & - \\
\hline
\end{tabular}

The results shown in Table 8 can be understood by analyzing the evolution of productive economic structures of South American countries, i.e., how the shares of their primary, secondary, and tertiary sectors changed during the sample period. Table 10 shows the value added for each sector of the economy as a percentage of GDP for the 10 countries included in the study. We can see that in recent decades the primary sector represents a smaller share of a nation's GDP and that secondary and tertiary sectors represent larger GDP shares. Argentina, Brazil and Chile have the largest elasticities reported in Table 8. This signifies that these countries' economies are goods-intensive in the secondary and tertiary sectors (industry and services). In the cases of Paraguay and Colombia, countries with lower elasticities, we can see that during the 1970s and the past decade, both countries reduced the share of their primary sectors and increased participation of their tertiary sectors.

In particular, Table 10 demonstrates that countries with a high GDP share generated in the primary sector (in relative terms) in the 1970s and a low share in the 1990s should have low elasticities in the relationship between energy consumption and GDP. Conversely, countries whose GDP share from the primary sector has declined significantly should show high elasticities in the relationship between energy consumption 


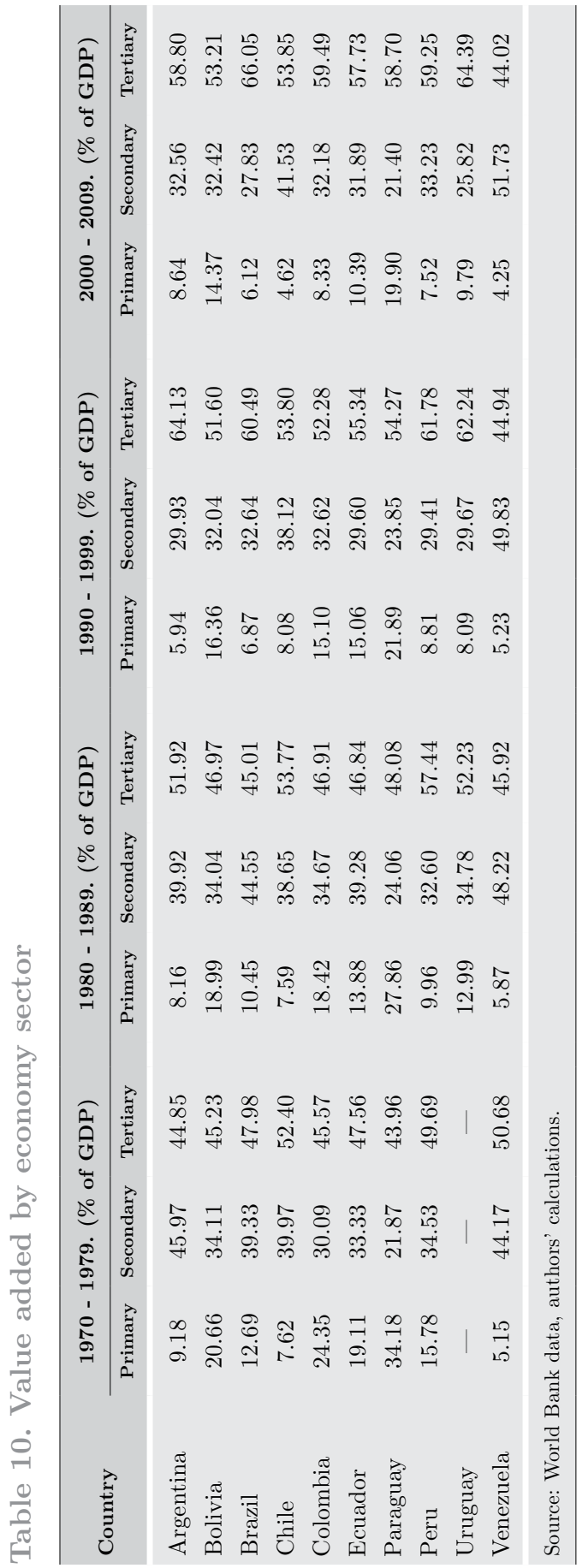


and GDP. One exception to this behavior is Argentina, which saw a small change in relative terms.

\section{Conclusions}

It is important to understand the effects of increased energy consumption on GDP so that economic policy makers can predict the impacts of implementing energy policies on a country's GDP. Our evidence reflects the existence of panel stationarity for Latin American countries, and our panel attests to bidirectional causality between energy consumption and GDP in all sample countries.

The literature investigates the impact of energy consumption on GDP for many countries using different techniques and methodologies. The results of these studies show that different methodologies lead to confusing and contradictory conclusions about this relationship. This paper estimates the elasticity of the long-run relationship of energy consumption-GDP and GDP-energy consumption for 10 countries in Latin America during the period from 1971 to 2007. We employ Pedroni's $(1999,2004)$ panel cointegration test to determine if a longrun relationship exists between the variables in equations (1) and (2). By using a cointegration test for panel data developed by Westerlund (2006), which accounts for possible cross-sectional dependence between countries and any existing structural breaks in the longrun relationship, we identify the long-run elasticities. In the sections above, we provide empirical evidence about policy maker's abilities to design and implement programs to promote energy conservation and efficiency. For example, a 1\% increase in energy consumption increases real GDP by $0.59 \%$ across the entire panel, while a $1 \%$ increase in real GDP increases energy consumption by $0.59 \%$ across the entire panel.

In this case, because there is a long-run relationship between energy consumption and GDP, it is understood that in the long run energy generates economic growth for Latin American countries. In the cases of Bolivia, Colombia, Ecuador, Paraguay and even Peru and Uruguay, the elasticity of energy consumption is low (below the regional average). In these countries, policy makers could implement energy conservation programs with low negative impacts in the short run. However, if there is truth to the feedback hypothesis, which suggests that energy consumption and GDP are interrelated and complementary over time in a bidirectional, causal relationship, then policies that promote the energy efficiency do not negatively affect GDP. In addition, according 
to the results of our panel stationarity tests, if shocks in energy consumption and GDP are temporary, stabilization policies will power long-lasting effects in the countries of Latin America. Finally, the result of our cointegration test suggests that energy consumption and GDP are endogenous variables in Latin American countries at the rate of the bidirectionality of causality. Another interesting result is that the methodology is better than those used previously, in the sense that it reflects the presence of structural breaks, controls endogeneity and includes the presence of cross-correlation between the countries concerned.

Countries such as Argentina, Brazil and Chile are energy-dependent, which means that policies that seek to conserve energy in the long run would have disastrous results on their economic growth. Additionally, this dependence on the part of some Latin American countries indicates the need to diversify energy sources, since those countries must weigh the need for sustainable economic growth against the environmental costs associated with excessive energy consumption.

Although it is difficult to make definitive conclusions about the energy policy of Latin American countries based on the empirical results presented in this paper, these findings serve to explain certain tools that can be used in conjunction with other studies in the decisionmaking process.

Future research could include variables such as physical capital, human capital and labor to estimate the long-run elasticities, following the methods of Mankiw, Romer and Weil (1992). This procedure would account for the fact that these factors of production are just as important as energy consumption. In addition, future research could extend the analysis to short-term relationships with a VEC model, as this model provides evidence that the series are cointegrated. Additionally, future research could evaluate energy efficiency policies not on the basis of energy conservation measures, but rather from the perspective of the efficiency of energy use in production processes. 


\section{REFERENCES}

Akarca, A.T. and T.V. Long (1980), "On the relationship between energy and GNP: A reexamination," Journal of Energy Development 5: 326-31.

Abosedra, S. and H. Baghestani (1991), "New evidence on the causal relationship between U.S. energy consumption and gross national product," Journal of Energy and Development 14: 285-92.

Al-Iriani, M.A. (2006), "Energy GDP relationship revisited: An example from GCC countries using panel causality," Energy Policy 34: 3342-50.

Breitung, J. (2000), "The local power of some unit root tests for panel data," Advances in Econometrics 15: 161-77.

Bai, J. and P. Perron (2003), "Computation and analysis of multiple structural change models," Journal of Applied Econometrics 18: 1-22.

Cheng, B.S. (1995), "An investigation of cointegration and causality between energy consumption and economic growth," Journal of Energy Development 21: $73-84$.

Choi, I. (2001), "Unit root test for panel data," Journal of International Money and Finance 20: 249-72.

Davison, A. and D. Hinckley (1997), Bootstrap methods and their application. Cambridge: Cambridge University Press.

Dichey, D. and W. Fuller (1979), "Distribution of the estimators for autoregressive time series with a unit root," Journal of the American Statistical Association 74: $427-31$.

Engle, R.F. and C. Granger (1987), "Co-integration and error-correction: Representation, estimation and testing," Econometrica 55(2): 251-76.

Erol, U. and E.S.H. Yu (1987), "On the causal relationship between energy and income for industrialized countries," Journal of Energy Development 13: $113-22$.

Fatai, K., L. Oxley, and F. Scrimgeour (2002), "Energy consumption and employment in New Zealand: Searching for causality," paper presented at NZAE Conference, Wellington, June 26-28, 2002.

Ghosh, S. (2002), "Electricity consumption and economic growth in India," Energy Policy 30: 125-29.

Glasure, Y. and A. Lee (1997), "Cointegration, error correction and relationship between GDP and energy: The case of South Korea and Singapore," Resource and Energy Economics 20: 17-25.

Granger, C. and P. Newbold (1974), "Spurious regressions in econometrics," Journal of Econometrics 2: 111-20.

Granger, C. (1969), "Investigating causal relations by econometric models and cross-spectral methods," Econometrica 37: 424-38.

Hadri, K. (2000), "Testing for stationarity in heterogeneous panel data," Econometric Journal 3: 148-61. 
Hwang, D. and B. Gum (1992), "The causal relationship between energy and GNP: The case of Taiwan," Journal of Energy and Development 16(2): 219-26.

Im, K., M. Pesaran, and Y. Shin (2003), "Testing for unit roots in heterogeneous panels," Journal of Econometrics 115: 53-74.

Kwiatkowski, D., P. Phillips, P. Schmidt, and Y. Shin (1992), "Testing the null hypothesis of stationarity against the alternative of unit root," Journal of Econometrics 54(1-3): 159-78.

Kraft, J. and A. Kraft (1978), "On the relationship between energy and GNP," Journal of Energy and Development 3(2): 401-03.

Lee, C. (2005), "Energy consumption and GDP in developing countries: A cointegrated panel analysis," Energy Economics 27: 415-27.

Lee, C. and C. Chang (2007), "Energy consumption and GDP revisited: A panel analysis of developed and developing countries," Energy Economics 29: $1206-23$.

Lee, C. and C. Chang (2008), "Energy consumption and economic growth in Asian economies: A more comprehensive analysis using panel data," Resource and Energy Economics 30: 50-65.

Lorde, T. and K. Guy (2009), "Energy consumption and economic growth in Latin America and the Caribbean: A panel cointegration approach," Central Bank of Barbados Research Department.

Johansen, S. (1988), "Statistical analysis of cointegration vectors," Journal of Economic Dynamics and Control 12(2-3): 231-54.

Johansen, S. (1991), "Estimation and hypothesis testing of cointegration vectors in Gaussian vector autoregressive models," Econometrica 59(6): 1551-80.

Maddala, G. and S. Wu (1999), "A comparative study of unit root test with panel data and a new simple test," Oxford Bulletin of Economics and Statistics 61: $631-52$.

Magazzino, C. (2011), "Energy consumption and aggregate income in Italy: Cointegration and causality analysis," Munich Personal RePEc Archive (MPRA), No. 28494.

Masih, A., and R. Masih (1996), "Energy consumption and real income temporal causality: Results from a multi-country study based on cointegration and error-correction modeling techniques", Energy Economics 18: 165-83.

Pedroni, P. (1999), "Critical values for cointegration tests in heterogeneous panels with multiple regressors," Oxford Bulletin of Economics and Statistics, Special Issue 0305-9049.

Pedroni, P. (2004), "Panel cointegration: Asymptotic and finite sample propierties of pooled time series with an application to the PPP hypothesis: New results," Econometric Theory 20: 597-627.

Squalli, J. (2007), "Electricity consumption and economic growth: Bounds and causality analyses of OPEC members," Energy Economics 29: 1192-1205.

Soytas, U., R. Sari, and O. Ozdemir (2001), "Energy consumption and GDP relations in Turkey: A cointegration and vector error correction analysis," 
Economics and business in transition: facilitating competitiveness and change in the global environment proceedings, Global Business and Technology Association: 838-44 .

Yu, E.S.H. and B.K. Hwang (1984), "The relationship between energy and GNP: Further results," Energy Economics 6: 186-90.

Yu, E.S.H. and J.Y. Choi (1985), "The causal relationship between energy and GNP: An international comparision," Journal of Energy and Development 10: $249-72$.

Westerlund, J. (2006), "Testing for panel cointegration with multiple structural breaks," Oxford Bulletin of Economics and Statistics 68: 10132. 
